\title{
As Cartas Educativas em Portugal: conceção, implementação e monitorização
}

\author{
Educational Charters in Portugal: conception, implementation and monitorization
}

Las Cartas Educativas en Portugal: diseño, implementación y monitorización

\author{
DORA FONSECA DE CASTRO* \\ LUÍS ROTHES**
}

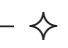

RESUMO - A Carta Educativa (CE) surge com a publicação do Decreto-Lei 7/2003, e que regulamenta, também, a criação dos Conselhos Municipais de Educação (CME). Em 2004 é celebrado um Protocolo entre o Ministério de Educação e a Associação Nacional dos Municípios Portugueses que parte da assunção do Decreto-Lei 7/2003 como "passo fundamental no sentido da concretização da descentralização administrativa na área da educação" constituindo-se como um normativo capital para a "execução da descentralização e territorialização de políticas educativas para o que conta com dois instrumentos fundamentais: o Conselho Municipal de Educação e as Cartas Educativas. Tendo em conta a análise dos normativos legais e alguns estudos realizados no plano da ação, fica claro que, o processo de elaboração e desenvolvimento e monotorização da Carta Educativa é ainda controlado pelo poder central, contrariando o discurso político-normativo que vê este documento como um instrumento estratégico de desenvolvimento da descentralização e territorialização das políticas educativas.
\end{abstract}

Palavras-chave - Cartas Educativas. Conselhos Municipais. Descentralização.

\begin{abstract}
Educational Charters (EC) appear with the publication of Decree-Law 7/2003, which regulates and also creates Municipal Councils of Education (MCE). In 2004 a Protocol between the Ministry of Education and the National Association of Portuguese Municipalities was signed and results from Decree-Law 7/2003 as "a fundamental step towards the realization of administrative decentralization in education" constituting itself as a capital normative for the "implementation of decentralization and territorialization of educational policies which has two key instruments: the Municipal Council of Education and Educational Charters. Taking into account the analysis of legal documents and action researches, it is clear that the process of drafting, developing and monitoring Educational Charters is still controlled by the central government, contrary to legal-political discourse that sees this document as a strategic instrument towards the progress of decentralization and territorialization of educational policies.
\end{abstract}

Keywords - Educational Charters. Municipal Councils. Decentralization.

RESUMEN - La Carta Educativa (CE) surge con la publicación del Decreto-Ley 7/2003, que, también, crea los Consejos Municipales de Educación (CME). En 2004 se firmó un Protocolo entre el Ministerio de Educación y la Asociación Nacional de Municipios Portugueses, que según el Decreto-Ley 7/2003 presenta "un paso importante hacia una descentralización administrativa efectiva en el ámbito de la educación", constituyéndose como una normativa esencial para la "consecución" de la descentralización y territorialización de la política educativa que cuenta con dos instrumentos fundamentales: el Consejo Municipal de Educación y la Carta Educativa. Considerando el análisis de los normativos jurídicos y algunos estudios realizados en el plan de la acción, queda claro que, el proceso de elaboración, desarrollo y monitorización de la Carta Educativa sigue siendo controlada por el gobierno central, contrariando el discurso político-normativo que ve este documento como un instrumento estratégico para la descentralización y el desarrollo territorial de las políticas educativas.

Palabras clave - Cartas Educativas. Consejos Municipales. Descentralización.

\footnotetext{
*Doutora em Educação pela Universidade de Aveiro (Aveiro, Portugal) e Professora no Instituto Politécnico do Porto (Porto, Portugal). E-mail: < doracastro@ ese.ipp.pt>.

** Doutor em Educação pela Universidade do Porto (Porto, Portugal) e Professor no Instituto Politécnico do Porto (Porto, Portugal).E-mail: <lrothes@ese.ipp.pt>.
} 


\section{A relação Poder Central e PODER LOCAL}

A publicação da Lei de Bases do Sistema Educativo (LBSE), Lei no 46/1986, de 14 de Outubro pode ser tomada como um marco significativo, em termos legislativos, para o desenvolvimento das ideias de participação e descentralização, na medida em que recusa o modelo burocrático e centralizado de administração na sua forma concentrada (LIMA, 1992; FORMOSINHO; MACHADO, 2000). A LBSE acabou, no entanto, por contribuir para a implementação de medidas destinadas à promoção de formas de desconcentração dos serviços de educação em Portugal e não propriamente descentralizadoras (LIMA, 1992). No que respeita aos discursos políticos, Flores (2005) assinala dois marcos importantes relacionados ao processo de descentralização. O primeiro corresponde ao contexto político marcado pela aprovação da LBSE (PORTUGAL, 1986), por se encontrar associado à retórica da descentralização, enquanto que o segundo corresponde ao Pacto Educativo para o Futuro (PORTUGAL, 1996), no qual se dava ênfase à territorialização e autonomia.

Nos anos oitenta começam a desenhar-se "novos desenvolvimentos" decorrentes da integração europeia, de novas reconfigurações políticas, económicas e sociais e da influência das várias estruturas supranacionais que emitem pareceres, recomendações com impacto nas várias realidades. Estas regulações crescentes à escala transnacional, o enfraquecimento do Estado-Educador e a impossibilidade do poder central dar respostas diferenciadas a um sistema educativo que se revela cada vez mais complexo "acentua a crise de legitimidade e de governabilidade e do próprio modelo" (BARROSO, 1999, p. 130), procurando o Estado "na localização das políticas, nos reajustamentos e nos compromissos locais, na redistribuição de competências, saídas para a crise geral que o atravessa" (CRUZ, 2012, p. 64). Nesta linha e seguindo de perto a autora referenciada, a territorialização pode ser considerada como "uma política nacional num contexto de crise de legitimação da acção do Estado, que, quebrando a lógica de Estado Educador delega poderes na comunidade reservando-se a um papel de regulação e de controlo (ibidem, p. 40).

As mudanças que vão acontecendo a diferentes escalas levam a multiregulações podendo gerar novos espaços de decisão, novas influências e novos atores protagonistas da ação pública em educação. A este propósito Barroso (2006b, p. 56-57) considera que:

a construção e a coordenação das políticas e a acção educativa não se resumem, nem se restringem à escala nacional, antes se alargam às escalas transnacional $\mathrm{e}$ local (...) na medida em que se partilham recursos e processos em espaços infra e supra nacionais. Interessa identificar as origens e os efeitos destes processos de regulação e, principalmente, perceber o dinamismo e a complexidade destas mudanças de escala muito para além das transferências, dos deslocamentos de competências entre a Europa, os estados nacionais, as regiões e as autarquias no que possam significar de modificação na regulação da acção pública em educação.

Apesar das multiregulações nos vários espaços e níveis de decisão, o local assume-se como um espaço de elevada importância na construção de ação pública em educação. Ferreira (2004, p. 61) entende que a valorização do local não é uma situação nova, considerando que a novidade na importância atribuída ao local se deve ao fato de a relocalização ocorrer "com o questionamento das instituições nacionais-estatais, e com o fenómeno da globalização", chamando a atenção para o facto de que a revalorização da descentralização, da autonomia e da participação dos atores ao nível local poder estar associada, de certa forma, às lógicas mercantis defendidas pela perspetiva neoliberal. Barroso (1998, p. 11) apesar de entender que, em alguns casos, a "territorialização" pode ser vista como uma medida promotora da introdução da "lógica de mercado", considera que é possível encará-la como um processo de "apropriação, por uma determinada comunidade, de diversos espaços sociais" (id.) baseando-se no que entende ser a "mobilização" como "reunião de um núcleo de atores com o fim de empreenderem uma ação coletiva" (id.).

Atualmente, não obstante as influências das tendências transnacionais e o facto de as políticas educativas nacionais apontarem para o aumento e transferência de competências para níveis de decisão local, ainda não se registam em Portugal avanços muito significativos nesse sentido, isto por razões diversas que se estendem desde as resistências e/ou ações desenvolvidas pelos diferentes atores sociais envolvidos nestes processos até às ambiguidades e contradições entre o discurso políticolegal e as ações reais desenvolvidas pela administração central e instâncias intermédias de gestão. Cruz (2012, p. 51) entende que desta "sobreposição de diferentes lógicas, discursos e práticas resultam políticas educativas de carácter ambíguo e compósito, caracterizadas pelo seu hibridismo".

Em Portugal, longe de uma efetiva descentralização, vão sendo apenas ensaiados alguns passos nesse caminho, sendo este processo tratado como uma mera técnica de gestão centrada na transferência de competências do poder central para o poder local, longe da assunção de descentralização como um "processo, um percurso, 
construído social e politicamente por diferentes actores (muitas vezes com estratégias e interesses divergentes) que partilham o desejo de fazer do "local', um lugar de negociação/uma instância de poder e um centro de decisão" (BARROSO, 2006a, p. 11). Apesar da retórica da descentralização, territorialização e contratualização alimentada por termos como participação, colaboração e parceria assiste-se, "simultaneamente, à manutenção de práticas centralizadas e burocráticas" (FERREIRA, 2005, p. 189), que são também "reproduzidas ao nível local, muitas vezes, com maior afinco do que foram ou são observadas noutros níveis da administração da educação" (id.), funcionando a descentralização como uma "figura retórica destinada a justificar outros modos de regulação que associam o modelo centralista/burocrático e o pós-burocrático" (BARROSO citado por CRUZ, 2012, p. 42).

Estamos perante um novo discurso que combina a necessidade de valorização do local ao nível da gestão da educação, da participação de distintos atores nessa gestão - enquadradas por lógicas gerencialistas que se servem de uma gramática gestionária invocando a competitividade, a prestação de contas, a rentabilização de recursos em prol da melhoria da qualidade na educação com a permanência de práticas centralistas e burocratizantes.

Várias investigações ${ }^{1}$ realizadas no plano da ação dos atores, nas diferentes instâncias das organizações educativas, vão mostrando que a ação se pode afastar do estabelecido ou do previsto. Neste sentido, poder-se-ia afirmar que à margem das estruturas formais que apontam para cadeias hierárquicas que promovem regulações no sentido descendente vertical e, que à partida, dificultariam o desenvolvimento da autonomia das organizações educativas, uma face mais oculta, e que diz respeito às dinâmicas reais dos atores sociais, parece revelar muitas ambiguidades e contradições, mostrando que os processos de desenvolvimento de autonomia não são movimentos lineares dependentes exclusivamente das estruturas formais. Em determinadas realidades, parecem emergir regulações no sentido das periferias para os centros de poder instituídos, e que nos remetem para a consideração da existência de outros centros de decisão e de espaços de autonomia administrativa e pedagógica.

As questões acima postas, já exploradas em várias dimensões organizacionais, revelam a importância e a centralidade da ação dos atores sociais no desenvolvimento das organizações educativas. Mesmo em sistemas educativos centralizados e organizados de forma hierárquica piramidal, como no caso português, parece ser possível identificar movimentos autonómicos, quer ao nível pedagógico, quer ao nível administrativo.

\section{A IMportânCIA dos MUNICÍPIOS No DESENVOLVIMENTO DAS POLÍTICAS EDUCATIVAS LOCAIS}

A tomada de consciência da importância das cidades na educação e do papel dos Municípios na ação educadora neste contexto da cidade tem também contribuído para a transferência de competências, no plano educativo, do poder central para os Municípios. Pinhal (2004) faz referência à importância do papel do $\mathrm{Mu}$ nicípio no desenvolvimento da ideia de cidade educadora e que nasceu em iniciativas desenvolvidas por várias organizações mundiais, em vários locais do mundo, tais como: a Agenda 21, o programa da Organização das Nações Unidas (ONU) decorrente da conferência de Rio de Janeiro sobre o ambiente e o desenvolvimento, em 1992; o movimento das cidades sustentáveis baseado na Carta de Aalborg, Dinamarca em 1994; a iniciativa da cidade de Barcelona, com a criação da Associação Internacional das Cidades Educadoras que fez nascer uma Carta de Princípios - a Carta das Cidades Educadoras aprovada pela Declaração de Barcelona; a organização Cidades e Governos Locais Unidos; o Congresso realizado em Lisboa em 2000, com o tema "A cidade, um espaço educacional para o novo milénio"; entre outros. A principal ideia preconizada por todas estas organizações e iniciativas e, aliás, bem presente na referida Carta das Cidades Educadoras, é aquela que reconhece que a cidade exerce e desenvolve, para além das suas funções tradicionais, uma função educadora, ou seja, promove o desenvolvimento de todos os seus habitantes ao longo da vida. Machado (2004) entende que a metáfora da cidade-educativa faz reconhecer a potencialidade educativa da cidade e vê a escola como uma das formas (ao lado de muitas outras) de levar a cabo o projeto educativo para determinado território, podendo o Município assumir a coordenação ao nível local. A importância da ação pública ao nível local tem vindo a ser explorada por vários autores que enfatizam a sua importância e sobretudo a constatação do desenvolvimento de políticas territoriais. Ferreira (2004, p. 61) diz-nos que "o local - espaço local, os atores locais, os dinamismos locais - tem sido alvo de um interesse crescente nas sociedades contemporâneas" e, ainda, que "a proliferação de noções como autonomia, participação, comunidade, território, contrato, projeto e parceria (...) constituem alguns exemplos desse renovado interesse" (id.). Também Lopes e Sanches (2004, p. 135) se referem ao interesse pelo local e, sobretudo, à colaboração entre os Municípios e as escolas como sendo resultado de uma política de territorialização que é motivada por diversos fatores, entre os quais, o renascer dos valores políticos e sociais. 
A valorização do papel do Município no desenvolvimento das políticas educativas locais é um aspeto considerado central para vários investigadores. Para Fernandes (2004), o Município, outrora numa posição marginal e subordinada aos objetivos nacionais do sistema educativo, deveria hoje constituir-se como dinamizador e coordenador de uma política educativa local, remetendo esta nova posição para novas relações interinstitucionais ao nível dos territórios educativos. O autor recorda que o Município era perspetivado, numa primeira fase, como um serviço periférico com a missão de dar "apoio à educação infantil e à educação básica obrigatória" (FERNANDES, 2004, p. 37), passando, numa segunda fase, a ser encarado como "um parceiro privado com uma função supletiva em relação ao sistema educativo público" e, numa terceira fase, considerado como "um participante público na promoção e coordenação local da política educativa" (id.). A primeira fase diz respeito ao período de 1976 a 1986, tempo que se seguiu à Revolução de Abril. Nesta época, o papel dos Municípios encontrava-se circunscrito à construção de espaços educativos, à aquisição de equipamentos e manutenção do ensino primário e educação infantil, à gestão dos transportes escolares, à gestão da ocupação dos tempos livres e à ação social escolar para os alunos que frequentavam a escola/Jardim de Infância. Na segunda fase, o Munícipio assume novas responsabilidades no que se refere ao campo do desenvolvimento de novas modalidades de educação, complementando a ação do Estado. Por esta altura, década de 1980, reconhece-se o Município, em termos legislativos, como parceiro social na definição das políticas educativas, passando a ter voz no Conselho Nacional de Educação (CNE) e também no Conselho Consultivo das Escolas Básicas e Secundárias (CCEBS). Assim, são levadas a cabo medidas que tornam o Município mais interventivo no plano educativo, mas na condição de parceiro, tal como qualquer outra entidade local. Decorrente das sugestões dadas pela Comissão de Reforma do Sistema Educativo (CRSE), é ativada a ideia da criação do Conselho Local de Educação (CLE), incluindo o Município como parte integrante da equipe de coordenação do órgão de direção dos Jardins de Infância e das Escolas Básicas e Secundárias (FERNANDES, 2004). A partir da década de 1990, que corresponde à terceira fase, o papel do Munícipio começa a alterar-se. De parceiro social passa a ser encarado, ainda que de forma pouco assumida, como membro ativo no desenvolvimento de políticas educativas ao nível local. Entre as várias mudanças operadas, salientam-se: i) as ações ao nível da promoção do sucesso educativo nos Territórios de Educativos de Intervenção Prioritária (TEIPs); ii) o papel importante que assumiu na expansão da educação de infância; iii) a inclusão de membros dos Municípios nos órgãos de Gestão das Escolas/Agrupamentos; iv) a criação dos Conselhos Municipais de Educação, atribuindo-se ao Município a competência para: a elaboração da Carta Educativa para o Concelho, a negociação dos contratos de autonomia das escolas/agrupamentos e aelaboração de projetos educativos municipais (FERNANDES, 2004).

Gradualmente, os Munícipios vão-se fazendo presentes no palco das decisões administrativas e de gestão das escolas. Não obstante reconhecermos que o processo de desenvolvimento de autonomia dos Municípios em Portugal foi marcado por avanços e recuos, poder-se-á perceber que, gradualmente, os Municípios foram tendo uma ação cada vez mais forte no desenvolvimento de políticas educativas locais, sendo esta, no entanto, sempre regulada pelo poder central que nunca abdicou de exercer uma ação dominadora, centralizada e burocratizada.

\section{OS CONSElHos Municipais de EdUCAÇÃo E AS CARTAS EDUCATIVAS}

Decorrente de várias recomendações, das quais se destacam os trabalhos da CRSE, surgem sinais, em termos do discurso político-normativo, de promoção de mecanismos que ampliem a participação dos diversos atores locais na gestão das políticas educativas ao nível dos territórios educativos. Embora não institucionalizado e devidamente enquadrado na lei, vários municípios desencadeiam a instalação do Conselho Local de Educação (CLE), defendendo-se entre a comunidade científica que a sua criação emerge do reconhecimento, pelos atores locais, da sua importância na gestão local da educação. Baixinho $(2009$, p. 7) entende que a "competência para os órgãos municipais poderem criar o Conselho Local de Educação (CLE) e elaborarem as Cartas Escolares é consolidada uma década depois da proposta apresentada pela Comissão da Reforma do Sistema do Sistema de Ensino (CRSE)", com a publicação do Decreto-Lei no 115 $\mathrm{A} / 98$, de 4 de maio que enquadra legalmente a autonomia da escola e, posteriormente, com a Lei no 159/99, de 14 de setembro que estabelece o quadro de transferência de atribuições e competências para as autarquias locais. Os CLE são entendidos no art. 2º do Decreto-Lei $\mathrm{n}^{\mathrm{o}}$ 115A/98 como "estruturas de participação dos diversos agentes e parceiros sociais com vista à articulação da política educativa com outras políticas sociais, nomeadamente em matéria de apoio socioeducativo, de organização de actividades de complemento curricular, de rede, horários e de transportes escolares". Fernandes $(1999$, p. 4) considera que, apesar de ser indiscutível a importância do CLE para o "desenvolvimento de um projeto educativo local", foram muitos os obstáculos que limitaram as potencialidades desse órgão tais como "as resistências institucionais, corporativas e individuais para a cooperação conjunta, o excessivo número de 
participantes, as competências puramente consultivas, a inexistência de um apoio logístico adequado, tornando-o excessivamente dependente de outras entidades"(id.).

Embora o CLE seja referido nos normativos ${ }^{2}$ publicados em 1998 e 1999, só em 2003 é que este órgão viria a ser regulamentado pelo poder central mas com outra designação: Conselho Municipal de Educação (CME).

O CME, regulamentado pelo Decreto-Lei $\mathrm{n}^{\mathrm{o}}$ 7/2003, de 15 de janeiro assume-se como um órgão de coordenação e consulta, que tem como objetivo promover a coordenação, ao nível do Município, da política Educativa (art. $3^{\circ}$ ) sendo considerada esta medida, ao nível do preâmbulo do normativo, como uma "nova visão estrutural do sistema educativo português e um passo da maior importância no sentido da aproximação entre os cidadãos e o sistema educativo, e de co-responsabilização entre ambos". Este normativo define específicamente a função, as competências e composição do $\mathrm{CME}$, sendo este facto, para vários investigadores, uma condicionante à partida de práticas autonómicas em termos da gestão das políticas educativas locais. É também considerado um retrocesso se compararmos com o seu antecessor, o CLE. A sua composição era um exemplo claro disso pois era determinada ao nível local e não imposta pelo poder central.Cruz (2012, p. 57) entende que este normativo constitui um "instrumento legislativo e regulamentar, de carácter multidimensional e híbrido (...)"adiantando, ainda a autora, que "o diploma apresenta a "dimensão simbólica de legitimação e de enquadramento dos CME no processo histórico das políticas de descentralização (...)", apresenta "referenciais de um modelo de entidade de intervenção local (...)" e uma "dimensão de multirregulação que implícita e/ou explicitamente orienta os comportamentos dos actores e delimita os seus espaços de intervenção e de interacção.

$\mathrm{O}$ facto de muitos Municípios criarem o CME é para Baixinho (2008, p. 113) "indiscutível para assegurar uma coordenação local entre todos os actores educativos e poder delinear um documento orientador, "Carta Educativa" (...) para o desenvolvimento de um projeto educativo local". Também Prates $(2009$, p. 4), tendo em conta uma investigação que realizou e que incidiu sobre os $\mathrm{CME}$, considera que a função mais relevante para o $\mathrm{CME}$, "consiste no acompanhamento do processo de elaboração da Carta Educativa", adiantando, ainda, que alguns atores locais entendem que o CME é um órgão "esvaziado de sentido, no atual contexto da progressiva transferência de competências para a Câmara Municipal" (id.) e que "todo o sistema pode funcionar sem a intervenção deste órgão" pois apenas é um órgão consultivo (id.). Cerca (2007) julga que o CME tem uma grande limitação ao nível da sua composição. Se comparado com o CLE, poder-se-á concluir que está limitado na representação dos serviços educativos. Segundo a autora, não há representação da direção das escolas/agrupamentos, da educação especial, da educação de adultos nem de outros serviços de educação não formal. Martins, Nave e Leite (2005) constatam, no estudo que realizaram na Região Norte, que o CME não tem uma efetiva representação das escolas. Cerca (2007) adianta que o CME é apenas um órgão de consulta sem poder deliberativo sobre as políticas pois as decisões continuam a ser tomadas pelo poder central constituindo como afirma Pinhal $(2004$, p. 1) a regulamentação dos CME "uma oportunidade perdida". Ribeiro (2005, p. 27) reafirma estas ideias frisando que existe um retrocesso no que diz respeito à "participação contextualizada e de vinculação de decisões", tendo como referência o CLE.

Contudo, o estudo ${ }^{3}$ de Cruz (2012) revela que existem diferentes visões de encarar o CME, nomeadamente em relação à importância que os atores lhe atribuem e à sua atuação e responsabilidades dos seus membros ao nível das políticas educativas locais.

\section{As CARTAS Educativas: CONCEÇão, IMPLEMENTAÇÃO E MONITORIZAÇÃO}

Apesar de no Decreto-Lei no 7/2003, de 15 de janeiro ser dado ênfase ao facto do CME poder fazer o acompanhamento do processo de elaboração da Carta Educativa (CE ) e de este documento ser considerado no mesmo diploma um instrumento crucial para o desenvolvimento das políticas educativas locais, a realidade parece contrariar esta ideia assumida no discurso político-legal. A CE é, a nível municipal, o instrumento de planeamento e ordenamento prospetivo de edifícios e equipamentos educativos a localizar no concelho, de acordo com as ofertas de educação e formação que seja necessário satisfazer, tendo em vista a melhor utilização dos recursos educativos, no quadro do desenvolvimento demográfico e socioeconómico de cada município. O conceito redutor de Carta Educativa, utilizado pelo legislador, centrado apenas na gestão do parque escolar e respetivos equipamentos e articulação das ofertas formativas, sempre definidas centralmente, limita a capacidade do documento se constituir como um efetivo instrumento de gestão de política educacional. Deste modo, é um documento que não traduz a escolha e implementação de uma verdadeira política educativa concelhia, não constituindo um instrumento resultante da participação ativa da comunidade educativa. Martins, Nave e Leite (2005) consideram que as escolas têm estado afastadas da elaboração das CEs.

A responsabilidade da elaboração da $\mathrm{CE}$ é, tal como determinada no diploma, do Município. Deverá, posteriormente, ser aprovada pela Assembleia Municipal, 
depois do parecer emitido pelo CME. Fica claro que o CME tem aqui um papel secundário no processo da conceção e elaboração da CE. É determinado, ainda, que o apoio técnico para a elaboração da $\mathrm{CE}$ é do foro do ME que terá que disponibilizar os meios e recursos necessários para a operacionalização desse serviço de assistência. A CE que integra o Plano Diretor Municipal (PDM) está sujeita a ratificação governamental, após parecer vinculativo do ME. Está também previsto que na criação e desenvolvimento das CEs deverá haver grande articulação entre o ME e os Municípios de forma a garantir uma eficaz gestão da rede educativa e da execução e cumprimento de programas e projetos supramunicipais. A forma como as CEs devem ser elaboradas é prevista e apresentada em anexo de um documento que resulta de um Protocolo estabelecido entre o $\mathrm{ME}$ e a Associação Nacional dos Municípios Portugueses (ANMP). O modelo de CE transmitido pela ANMP a todos os Municípios do país apresenta um conjunto de itens a serem contemplados na sua elaboração, bem como um protótipo de texto que poderá ser utilizado. Cabe, ainda, ao $\mathrm{ME}$ e aos Municípios reavaliar obrigatoriamente, de cinco em cinco anos, a necessidade de revisão da CE. O processo de criação, desenvolvimento, monitorização e eventual revisão ou atualização das CEs é fortemente regulado e condicionado por duas entidades (o ME e a ANMP), transparecendo uma visão técnico-instrumental e não tanto um processo participativo de natureza política. Contrariando o preconizado na lei sobre o papel central do CME no desenvolvimento das CEs, na prática, este órgão acaba por ficar numa situação periférica no que diz respeito ao processo de acompanhamento e reformulação das CEs, em relação ao ME e aos Municípios que são os verdadeiros protagonistas nesse processo.

\section{CONSIDERAÇÕES FINAIS}

A publicação do Decreto-Lei no 7/2003, de 15 de janeiro regulamenta o modo como são transferidas algumas competências em matéria de educação do poder central para o poder local e que passam pela criação do Conselho Municipal de Educação e da Carta Educativa. Contudo, tendo em conta o funcionamento real e as ações desenvolvidas pelos CMEs bem como o processo de criação, desenvolvimento e monitorização das CEs, podemos inferir que quando falamos de transferência de poderes do poder central para o plano local continuamos apenas no plano da retórica. Fica claro que, no que diz respeito à elaboração e desenvolvimento da $\mathrm{CE}$, considerada ao nível do discurso político-normativo um documento estratégico de gestão, o CME não tem efetivamente um papel ativo ficando-lhe reservado, na prática, a mera ação de consulta e de emissão de pareceres relativamente ao processo que é assumido pelo ME e pelo Município ou pelos seus representantes ou serviços requisitados por aquelas estruturas. Fica ainda evidente o controle do poder central sobre os processos desenvolvidos ao nível local, quer no diz respeito à regulamentação estreita da composição e competências e ação do CME, quer na regulamentação da elaboração, acompanhamento e controle das CE. Podemos ainda perceber tendo em conta os estudos levados a cabo que muitas das decisões do poder local ou recomendações do CME já foram tomadas previamente pelo poder central, tendo estas estruturas ao nível local, apenas o papel de legitimação dessas decisões. Continuam ainda a ocorrer situações que comprometem o cumprimento da legislação no que diz respeito à tomada de decisões ao nível local e que decorrem de ações levadas a cabo pelo poder central que vem alterar o estipulado pelos atores locais, sendo disso exemplificativo a reorganização da rede educativa, imposta recentemente para todo o país, pelo ME contrariando algumas decisões assumidas nas várias CEs ao nível municipal. Estudos recentes revelam, no entanto, que com as mesmas regulações do poder central, os atores, no plano de ação, vão percecionando o CME e as CEs de formas distintas e agindo e participando de modo diferenciado, equacionando-se que poderá ser possível que em alguns Municípios o CME venha assumir-se de facto como um espaço mais interventivo no plano da gestão local de educação e a CE como um instrumento efetivo de política educativa local.

\section{REFERÊNCIAS}

BAIXINHO, António Fernandes. Educação e autarquias: lógicas de ação do poder autárquico face ao poder central e aos micropoderes locais. In: CONGRESSO PORTUGUÊS DE SOCIOLOGIA, 6., 2008, Lisboa. Anais. Lisboa: Universidade Nova de Lisboa, Faculdade de Ciências Sociais e Humanidades, 2008. p. 1-13.

BARROSO, João. Os fantasmas da autonomia. Rumos, n. 23, jul./set., p. 12-16, 1998.

BARROSO, João. A escola entre o local e o global - perspectivas para o século XXI: o caso de Portugal. In: (Org.). A escola entre o local e o global: perspectivas para o século XXI. Lisboa: Educa, 1999, p. 129-142 (Educa-Organizações, 4).

BARROSO, João Introdução: a investigação sobre a regulação das políticas de educação em Portugal. In: (Org.). A regulação das políticas públicas de educação: espaços, dinâmicas e actores. Lisboa: Educa, 2006a, p. 11-39.

BARROSO, João. O Estado e a educação: a regulação transnacional, a regulação nacional e a regulação local. In: . (Org.). A regulação das políticas públicas de educação: espaços, dinâmicas e actores. Lisboa: Educa, 2006b, p. 41-70. CASTRO, Dora. A Gestão Intermédia nos Agrupamentos de Escolas: Os Coordenadores de Estabelecimento e as Lideranças Periféricas. 2010. Tese (Doutoramento em Ciências de Educação) - Universidade de Aveiro, Aveiro. 2010. 
CERCA, Inês. Poder local e educação: que relação? A descentralização de competências educativas para o poder local. 2007. 330 f. Dissertação (Mestrado em Sociologia) - Faculdade de Economia, Universidade de Coimbra, Coimbra, 2007.

COSTA, Jorge Adelino. Projetos em Educação. Contributos de análise organizacional. Aveiro: Universidade de Aveiro, 2007.

CRUZ, Clara. Conselhos Municipais de Educação: política educativa e acção pública. 2012. 282 f. Tese (Doutoramento em Educação) - Instituto de Educação, Universidade de Lisboa, Lisboa. 2012.

FERNANDES, António Sousa. Contextos da intervenção educativa local e a experiência dos municípios portugueses. In: FORMOSINHO, João; FERNANDES, António; MACHADO, Joaquim; FERREIRA, Fernando (Org.). Administração da educação: lógicas burocráticas e lógicas de mediação. Porto: ASA, 2005. p. 193-223.

FERNANDES, António Sousa. Município, cidade e territorialização educativa. In: COSTA, Jorge Adelino; NETO-MENDES, António; VENTURA, Alexandre (Org.). Políticas e gestão local da educação. Aveiro: Universidade de Aveiro, 2004. p. 35-43.

FERNANDES, António Sousa. Descentralização educativa e intervenção municipal. Noesis, n. 50, abr.-jun. 1999. Disponível em: $<$ http://area.dgidc.minedu.pt/inovbasic/edicoes/noe/noe50/ index.htm>. Acesso em: 21 fev. 2013.

FERREIRA, Fernando Ilídio. Educação e local: animação, gestão e parceria. In: COSTA, Jorge Adelino; NETO-MENDES, António; VENTURA, Alexandre (Org.). Políticas e gestão local da educação. Aveiro: Universidade de Aveiro, 2004. p. 61-80.

FERREIRA, Fernando Ilídio. Os agrupamentos de escolas: lógicas burocráticas e lógicas de mediação. In: FORMOSINHO, João; FERNANDES, António; MACHADO, Joaquim; FERREIRA, Fernando (Org.). Administração da educação: lógicas burocráticas e lógicas de mediação. Porto: ASA, 2005. p. 265-319.

FORMOSINHO, João; MACHADO, Joaquim. Autonomia, projeto e liderança. In COSTA, Jorge; NETO-MENDES, António; VENTURA, Alexandre (Org.). Liderança e estratégia nas organizações escolares. Aveiro: Universidade de Aveiro, 2000. p. 185-199.

FLORES, Manuel. Agrupamentos de escolas: indução política e participação. Coimbra: Almedina, 2005.

LIMA, Licínio. A escola como organização e a participação na organização escolar. Braga: Universidade do Minho/ Instituto de Educação e Psicologia/Centro de Estudos em Educação e Psicologia, 1992.

LOPES, Célia; SANCHES, Maria de Fátima. Génese de um agrupamento vertical de escolas: continuidades, potencialidades e mudanças na política autárquica da educação. In: COSTA, Jorge Adelino, NETO-MENDES, António; VENTURA, Alexandre (Org.). Políticas e gestão local da educação. Aveiro: Universidade de Aveiro, 2004. p. 135-151.

MACHADO, Joaquim. Cidade educadora e coordenação local da educação. In: FERNANDES, António; FERREIRA, Fernando; MACHADO, Joaquim; FORMOSINHO, João (Org.). Administração da educação: lógicas burocráticas e lógicas de mediação. Porto: ASA, 2005. p. 225-264.
MACHADO, Joaquim. Escola, município e cidade educadora: a coordenação local da educação. In: COSTA, Jorge Adelino Costa; NETO-MENDES, António; VENTURA, Alexandre (Org.). Políticas e gestão local da educação. Aveiro: Universidade de Aveiro, 2004. p. 161-172.

MARTINS, Jorge; NAVE, Gracinda; LEITE, Fernando. As autarquias e a educação em 2001/2002, na Região Norte. Porto: Projecto Autarquias/Educação, 2005. (texto policopiado)

PINHAL, João. Os municípios e a provisão pública de educação. In: COSTA, Jorge Adelino; NETO-MENDES, António; VENTURA, Alexandre (Org.). Políticas e gestão local da educação. Aveiro: Universidade de Aveiro, 2004. p. 45-60.

PORTUGAL. Assembleia da República do Programa XI Governo Constitucional. Programa de Aprovação à Assembleia da República "Pacto Educativo para o Futuro". Sessão de 12 de Junho de 1996. Diário da República, n. 083, p. 2. 777, 12 jun. 1996.

PORTUGAL. Decreto-Lei n. 115-A, de 4 de maio de 1998. Estabelece o regime de autonomia, administração e gestão dos estabelecimentos de educação pré-escolar e dos ensinos básico e secundário. Diário da República, Lisboa, n. 102, I Série - A, 4 maio 1998.

PORTUGAL. Decreto-Lei n. 7, de 15 de janeiro de 2003. Reativa os Conselhos Municipais de Educação e regulamenta as cartas Educativas Municipais. Diário da República, Lisboa, n. 12, I Série - A, 15 janeiro 2003.

PORTUGAL. Lei n. 41, de 22 de agosto de 2003. Introduz alterações na composição do CME. Diário da República. Lisboa, n. 193, I Série - A, 22 de agosto 2003.

PORTUGAL. Lei n. 46, de 14 outubro de 1986. Lei de Bases do Sistema Educativo Português. Diário da República, Lisboa, n. 237, Série I, 14 out. 1986.

PORTUGAL. Lei n. 159, de 14 de Setembro de 1999. Define o quadro de transferências de atribuições e competências para as autarquias locais. Diário da República, Lisboa, n. 215/99, I Série - A, 14 set. 1999.

PRATES, Maria Rosário. Conselho Municipal de Educação: que papel em face dos recentes normativos? In: CONGRESSO DA SOCIEDADE PORTUGUESA CIÊNCIAS DE EDUCAÇÃO, 10., Bragança. 2009, Anais. Bragança: Escola Superior de Educação do Instituto Politécnico, 2009, p. 1-15.

RIBEIRO, Rogério. Conselho local/municipal de educação. Da construção política do "local" à edificação jurídica de um espaço dito de participação contextualizada no campo educativo: constrangimentos e ambigüidades. Porto, 2005, 249 f. Dissertação (Mestrado em Educação) - Faculdade de Psicologia e de Ciências da Educação, Universidade do Porto.

\section{NOTAS}

1 COSTA, 2007; CASTRO, 2010; CRUZ, 2012.

2 DL 115 A/98 de 4 de maio e Lei no 159/99, de 14 de setembro.

3 Tese de Doutoramento realizada na Universidade de Lisboa.

Artigo recebido em janeiro 2014.

Aprovado em junho 2014. 